\title{
The acute phase response and exercise: court and field sports
}

\author{
K E Fallon, S K Fallon, T Boston
}

\begin{abstract}
Objective-To determine the presence or absence of an acute phase response after training for court and field sports. Participants-All members of the Australian women's soccer team $(n=18)$ and all members of the Australian Institute of Sport netball team $(n=14)$.

Methods-Twelve acute phase reactants (white blood cell count, neutrophil count, platelet count, serum iron, ferritin, and transferrin, percentage transferrin saturation, $\alpha_{1}$ antitrypsin, caeruloplasmin, $\alpha_{2}$ acid glycoprotein, $\mathrm{C}$ reactive protein, and erythrocyte sedimentation rate) were measured during a rest period and after moderate and heavy training weeks in members of elite netball and women's soccer teams.

Results-Responses consistent with an acute phase response were found in five of 24 tests in the soccer players, and in three of 24 tests in the netball players. Responses in the opposite direction were found in seven of 24 tests in the soccer players and two of 24 tests in the netballers. The most sensitive reactant measured, C reactive protein, did not respond in a manner typical of an acute phase response.

Conclusion-An acute phase response does not seem to occur as a consequence of the levels of training typical of elite female netball and soccer teams. This has implications for the interpretation of biochemical variables in these groups.

(Br F Sports Med 2001;35:170-173)
\end{abstract}

Keywords: acute phase response; iron; plasma proteins; inflammation

Department of Sports Medicine, Australian Institute of Sport, Belconnen, ACT, Australia

K E Fallon

S K Fallon

Department of Physiology

T Boston

Correspondence to: Associate Professor Fallon, Department of Sports Medicine, Australian Institute of Sport, PO Box 176, Belconnen, ACT 2616, Australia

Accepted 29 January 2001
The acute phase response is a common reaction to a range of threats to homoeostasis including bacterial infection, surgery, burns, neoplasia, tissue infarction, inflammatory diseases, ${ }^{1}$ and prolonged exercise. ${ }^{2}$ The response includes metabolic changes such as negative nitrogen balance, changes in lipid metabolism, alterations in serum concentrations of cations, changes in iron metabolism, leucocytosis, complement activation, and increases in proteins primarily produced in the liver. ${ }^{3}$ Concentrations of albumin, transthyretin, $\alpha$ fetoprotein, $\alpha_{2}$ acid glycoprotein, and transferrin decrease during the response. Changes related to iron metabolism also occur, including increased tissue storage iron (increased serum ferritin) and decreased serum iron, total iron binding capacity, and transferrin, and transferrin saturation. ${ }^{45}$

A number of studies have documented aspects of the acute phase response after exercise of a duration that would be expected to induce significant damage to skeletal muscle. ${ }^{6-12}$ No data are available on the acute phase response in relation to court and field sports.

Documentation of the extent and nature of the acute phase response to various types of exercise is important, as changes related to the response may need to be taken into account for interpretation of haematological and biochemical measurements made during and after participation in sport.

The aim of this prospective study was therefore to determine the presence or absence of the acute phase response in sports representative of a wide range of field and court sports.

\section{Methods}

All procedures conformed to the National Health and Medical Research Council guidelines for experimentation with human subjects and all subjects gave their written informed consent before participation in the study.

The subjects were all members of the Australian women's soccer team $(n=18)$ or the Australian Institute of Sport netball team $(n=$ 14). As it is difficult to assess elite athletes in an absolutely rested condition, the pretraining blood sample was taken from the netball group on their return from summer vacation before they started routine training, and from the soccer group after they had taken a two week break from routine training. The second soccer sample was taken after five months of training during a week selected by the coach as a moderate training week, and the third sample was taken nine months from baseline after a week selected by the coach as a heavy training week. The second netball sample was taken after five months of training during a week selected by the coach as a hard training week, and the third sample was taken nine months from baseline after a week selected by the coach as a moderate training week. Duration and type of training in each of the seven days before blood collection was determined by athlete questionnaire and review of coaching records.

Soccer training consisted of running, cycling, weight training, and training on the soccer pitch. In the week considered to be moderate training, mean duration of training was 12.9 hours, and, in the intense training week, it was 9.3 hours. Netball training consisted of weight training, court work, and practice games. In the week considered to be moderate 
Table 1 Subject characteristics

\begin{tabular}{lrr}
\hline & \multicolumn{1}{l}{ Netball } & \multicolumn{1}{c}{ Soccer } \\
\hline Age (years) & $18.4(0.8)$ & $23.0(5.0)$ \\
Height $(\mathrm{cm})$ & $179.5(7.1)$ & $167.7(7.9)$ \\
Weight $(\mathrm{kg})$ & $70.7(10.6)$ & $61.9(7.1)$ \\
\hline
\end{tabular}

Values are means (SD).

training, mean duration of training was 10.5 hours, and, in the intense training week, it was 10.3 hours.

Exclusion criteria included the presence of an acute or chronic inflammatory disease, infection, or injury and use of antiinflammatory medication or supplements containing iron.

On three occasions, $20 \mathrm{ml}$ blood was drawn from an antecubital vein, using a sterile technique, immediately after the subject had laid down. Samples were immediately transferred to a laboratory adjacent to the blood collection area and were processed within 60 minutes. All samples were obtained between 8 am and $9 \mathrm{am}$.

Table 2 Acute phase reactants in netball players

\begin{tabular}{llll}
\hline Variable & Resting & Heavy training & Moderate training \\
\hline White cell count $\left(\times 10^{9} / \mathrm{l}\right)$ & $6.37(1.23)$ & $6.64(1.10)$ & $7.38(1.26)$ \\
Neutrophil count $\left(\times 10^{9} / \mathrm{l}\right)$ & $3.22(0.68)$ & $3.30(0.75)$ & $3.98(1.22)$ \\
Platelet count $\left(\times 10^{9} / \mathrm{l}\right)$ & $217(36)$ & $229(57)$ & $229(56)$ \\
ESR $(\mathrm{mm} / 1 \mathrm{st} \mathrm{h})$ & $12(6)$ & $6.6(3.8)^{\star}$ & $8.1(4.7)^{\star}$ \\
$\mathrm{C}$ reactive protein $(\mathrm{mg} / \mathrm{l})$ & $2.33(1.21)$ & $2.52(0.68)$ & $1.66(0.89)$ \\
Caeruloplasmin $(\mathrm{g} / \mathrm{l})$ & $0.441(0.154)$ & $0.521(0.172)$ & $0.545(0.179)^{\star}$ \\
$\alpha_{1}$ antitrypsin $(\mathrm{g} / \mathrm{l})$ & $1.65(0.36)$ & $1.83(0.31)$ & $1.85(0.29)^{\star}$ \\
$\alpha_{2}$ acid glycoprotein $(\mathrm{mg} / \mathrm{dl})$ & $82.9(17.4)$ & $89.8(21.0)$ & $99.2(31.2)$ \\
\hline
\end{tabular}

Values are means (SD).

${ }^{\star} \mathrm{p}<0.05 v$ resting (two tailed Student's $t$ test).

ESR, Erythrocyte sedimentation rate.

Table 3 Iron related variables and creatine kinase activity in netball players

\begin{tabular}{llll}
\hline Variable & Resting & Heavy training & Moderate training \\
\hline Iron $(\mathrm{mmol} / \mathrm{l})$ & $16.9(6.6)$ & $18.8(6.3)$ & $19.8(7.8)$ \\
Ferritin $(\mathrm{ng} / \mathrm{ml})$ & $53.6(39.7)$ & $42.9(28.8)$ & $38.2(26.1)$ \\
Transferrin $(\mathrm{g} / \mathrm{l})$ & $3.19(0.53)$ & $3.54(0.53)$ & $3.78(0.47)$ \\
Transferrin satn (\%) & $24(10)$ & $24(9)$ & $23(10)$ \\
Creatine kinase (U/l) & $180(132)$ & $208(90)$ & $145(69)$ \\
\hline
\end{tabular}

Values are means (SD).

Table 4 Acute phase reactants in women soccer players

\begin{tabular}{llll}
\hline Variable & Resting & Moderate training & Heavy training \\
\hline White cell count $\left(\times 10^{9} / 1\right)$ & $7.49(2.50)$ & $5.96(1.47)^{\star}$ & $5.88(1.57)^{\star}$ \\
Neutrophil count $\left(\times 10^{9} / 1\right)$ & $4.28(1.84)$ & $3.46(1.04)$ & $3.05(0.94)^{\star}$ \\
Platelet count $\left(\times 10^{9} / 1\right)$ & $248(41)$ & $242(37)$ & $226(46)^{\star}$ \\
ESR $(\mathrm{mm} / 1 \mathrm{st} \mathrm{h})$ & $9(5)$ & $9(7)$ & $9(4)$ \\
C reactive protein $(\mathrm{mg} / \mathrm{l})$ & $2.68(1.70)$ & $2.48(1.72)$ & $1.62(1.32)^{\star}$ \\
Caeruloplasmin $(\mathrm{g} / \mathrm{l})$ & $0.48(0.14)$ & $0.47(0.13)$ & $0.44(0.15)^{\star}$ \\
$\alpha_{1}$ antitrypsin $(\mathrm{g} / \mathrm{l})$ & $1.86(0.30)$ & $1.99(0.29)^{\star}$ & $1.76(0.27)$ \\
$\alpha_{2}$ acid glycoprotein $(\mathrm{mg} / \mathrm{dl})$ & $79.1(19.4)$ & $77.3(19.5)$ & $65.4(12.9)^{\star}$ \\
\hline
\end{tabular}

Values are means (SD).

${ }^{\star} \mathrm{p}<0.05 v$ resting (two tailed Student's $t$ test).

ESR, Erythrocyte sedimentation rate.

Table 5 Iron related variables and creatine kinase activity in women soccer players

\begin{tabular}{llll}
\hline Variable & Resting & Moderate training & Heavy training \\
\hline Iron $(\mathrm{mmol} / \mathrm{l})$ & $25.6(9.5)$ & $14.9(6.6)^{\star}$ & $16.3(6.5)^{\star}$ \\
Ferritin $(\mathrm{ng} / \mathrm{ml})$ & $54.2(27.8)$ & $52.5(22.5)$ & $59.3(37.0)$ \\
Transferrin $(\mathrm{g} / \mathrm{l})$ & $3.16(0.37)$ & $2.97(0.38)$ & $3.27(0.41)$ \\
Transferrin satn (\%) & $36(13)$ & $22(9)^{\star}$ & $21(7)^{\star}$ \\
Creatine kinase (U/1) & $151(189)$ & $315(166)$ & $194(71)$ \\
\hline
\end{tabular}

Values are means (SD).

${ }^{\star} \mathrm{p}<0.05 v$ resting (two tailed Student's $t$ test).
Serum iron, transferrin, ferritin, total iron binding capacity, percentage transferrin saturation, creatine kinase activity, and haptoglobin were measured on a Hitachi 911 analyser using Boehringer-Mannheim reagents. $\mathrm{C}$ reactive protein, $\alpha_{1}$ antitrypsin, and $\alpha_{2}$ acid glycoprotein were measured by nephelometry on a Beckmann Array Protein System (Beckmann, Brea, California, USA) using Beckmann reagents. Erythrocyte sedimentation rate (ESR) was measured using standard manual methods.

All dependent variables were analysed using a two tailed Student's $t$ test for differences from resting levels. Statistical analysis was performed using Statistica, version 5.1 (StatSoft Inc, Tulsa, Arizona, USA).

\section{Results}

Table 1 shows the characteristics of the subjects.

In the soccer group, 13 subjects reported no training in the 72 hours before the start of the study, three had trained lightly up to 48 hours before the start, and two had trained lightly within 48 hours of the baseline measurements. In the netball group, no subject had performed any training within 72 hours of baseline measurements. In this group, mean (SD) total training time during the week before baseline was 3 (0.6) hours. Table 2 summarises the findings for acute phase reactants in the netball players. ESR had decreased after both heavy and moderate training weeks. Serum caeruloplasmin and $\alpha_{1}$ antitrypsin had increased after the moderate training week.

Table 3 summarises the findings for iron related variables and creatine kinase activity in the netball players. No significant changes were found in these variables.

Table 4 gives the findings for acute phase reactants in the female soccer players. After the heavy training week, white cell count had decreased and $\alpha_{1}$ antitrypsin had increased, and after the moderate training week, significant decreases were found in the white cell count, neutrophil count, platelet count, C reactive protein, caeruloplasmin, and $\alpha_{2}$ acid glycoprotein.

Table 5 summarises the findings for iron related variables and creatine kinase activity in the female soccer players. Serum iron and percentage transferrin saturation were decreased after both the moderate and heavy training weeks.

\section{Discussion}

Athletes, particularly those at the elite level, are often subjected to multiple blood tests each year. Most of the tests are for screening purposes, and there appears to be an almost obsessional interest in iron related variables. The correct interpretation of these tests is therefore important, and the effects of exercise on serum levels of various variables need to be taken into account. Indeed a recent paper ${ }^{13}$ suggested that serum ferritin may not be an appropriate indicator of iron status in women training for judo. In support of this suggestion, the authors use evidence from studies of endurance running that the presence of an 
acute phase response affects serum ferritin levels. However, they do not provide any evidence that this response occurs during the activity that is the subject of their paper (judo) or during activities of a similar nature.

Although no data are available on the occurrence of an acute phase response after training in court and field sports, a number of authors have shown aspects of the acute phase response in endurance exercise. Weight et al showed increases in white cell count and $\mathrm{C}$ reactive protein immediately after a marathon. At 24 hours after the event, haptoglobin was significantly increased, as was fibrinogen. In response to running $25 \mathrm{~km}$ a day for four days, Dufaux et $a l^{7}$ found an increase in $\mathrm{C}$ reactive protein on days 3 and 5 but no change in C3 and C4. Immediately after a $100 \mathrm{~km}$ run, Poortmans and Haralambie ${ }^{8}$ found increased albumin, transferrin, and $\alpha_{1}$ glycoprotein and decreased haptoglobin, and on the following day a persistent decrease in haptoglobin and increases in $\alpha_{1}$ glycoprotein and $\alpha_{1}$ antitrypsin. Taylor et al assessed the response to a $160 \mathrm{~km}$ triathlon. Immediately after and 30 minutes after the event, an increase was found in white cell count, and serum iron and transferrin were decreased. At 24 hours after the run, $C$ reactive protein was raised. In a study based on iron related variables in which runners covered 50 $\mathrm{km}$ a day for 20 days, no change was found in serum iron, percentage transferrin saturation, ferritin, and transferrin at the end of the event. ${ }^{11}$

Dickson $e t a l^{10}$ found a significant increase in serum ferritin and no change in haptoglobin 48 hours after a $160 \mathrm{~km}$ run. They indicated that athletes who train hard every day may have falsely high serum ferritin levels, which may not correctly reflect iron stores. They recommended that, in long distance runners, ferritin measurements be made only after at least 14 days of rest. As athletes are unlikely ever to take such a long rest period, they suggested that serum ferritin levels about 35\% above those normally taken to indicate iron deficiency be considered to be highly suspicious of iron deficiency in actively training runners. In general internal medicine, the difficulty of interpreting ferritin values in the presence of an acute phase response has led to recommendations of threshold ferritin values of between 45 and 100 $\mu \mathrm{g} / \mathrm{l}$ for the diagnosis of iron deficiency in the presence of chronic disease. ${ }^{14}$

The recommendation of Dickson et $a l^{10}$ and the desire to minimise errors in the diagnosis of deficient iron stores in athletes may have influenced the supplementation practices of doctors, coaches, and athletes over the last two decades. Anecdotal reports indicate that recommendations for iron supplementation at ferritin levels $>50 \mu \mathrm{g} / 1$ were commonplace in the 1980s.

The optimum level of ferritin below which iron supplementation is recommended for athletes is unclear. Nielsen and Nachtigall ${ }^{15}$ indicate that $42 \%$ of 26 sport centres surveyed in Germany recommend supplementation for male athletes at serum ferritin levels greater than $30 \mu \mathrm{g} / 1$ and $49 \%$ recommend supplementation for female athletes at ferritin levels greater than $26 \mu \mathrm{g} / \mathrm{l}$. They suggest that a large number of clinics begin supplementation at low levels of ferritin $(25 \mu \mathrm{g} / \mathrm{l})$. These authors recommend supplementation when the level is less than $35 \mu \mathrm{g} / 1$ with continuation to a target value of $60 \mu \mathrm{g} / 1$.

On the other hand, another recent review ${ }^{16}$ indicated that, under normal training conditions, if the ferritin level is above $20-30 \mathrm{ng} / \mathrm{ml}$ and the transferrin saturation above $16 \%$ iron, supplements are not necessary.

In view of the large amount of high quality data available on indicators of iron deficiency in the general population and the relative paucity of such data in the athletic population, particularly that verified by bone marrow biopsy or measurement of serum transferrin receptor, it would be useful if data from general medicine could be applied to athletes and used for decisions about supplementation. Although other factors may need to be considered, this would be facilitated if the presence of an acute phase reaction to various types of athletic training could be confirmed or excluded. As an example, in a group of anaemic patients, Mast et $a l^{17}$ showed that, for iron storage deficiency, a serum ferritin of $30 \mu \mathrm{g} / 1$ had a sensitivity of $92 \%$, specificity of $98 \%$, and a positive predictive value of $92 \%$. Although a serum ferritin level of $12 \mu \mathrm{g} / \mathrm{l}$ is a highly specific indicator of iron deficiency, ${ }^{18}$ in this study this level combined a high specificity (98\%) with low sensitivity $(25 \%)$ and moderate positive predictive value $(75 \%)$. After analysis of a subgroup of otherwise healthy young women from this study, the authors indicated that serum ferritin should be considered the test of choice for assessing the need for iron treatment in this group and indicated that a level of $30 \mu \mathrm{g} / 1$ was an appropriate cut off point. A serum ferritin concentration of $30 \mu \mathrm{g} / 1$ thus appears to be a reasonable indicator of iron deficiency and could be used as such in the female athletic population, particularly if an acute phase response could be shown to be absent.

To facilitate this process, the present study specifically investigates the presence of an acute phase response in court and field sports. In the female soccer players, 12 acute phase reactants were measured during training periods on two occasions. Responses consistent with an acute phase response were found in five of 24 tests. Serum iron and percentage transferrin saturation decreased after both heavy and moderate training weeks, and $\alpha_{1}$ antitrypsin increased after the moderate intensity week. Responses that may be interpreted as being in the opposite direction from an acute phase response were also found in the soccer group. In the moderate intensity week, the white cell count decreased, and, after the heavy training week, white cell count, neutrophil count, platelet count, $\mathrm{C}$ reactive protein, caeruloplasmin, and $\alpha_{2}$ acid glycoprotein all decreased.

In the female netball players, 12 acute phase reactants were measured during training periods on two occasions. Responses consistent 
with an acute phase response were found in three of 24 tests. Serum caeruloplasmin and $\alpha_{1}$ antitrypsin had increased significantly after the moderate training week and $\alpha_{2}$ acid glycoprotein had increased significantly after the high intensity week. Responses that may be interpreted as being in the opposite direction from an acute phase response also occurred in the netball group. In the moderate intensity week, ESR decreased, and ESR fell after the heavy training week.

Of particular interest is the response of C reactive protein, a highly sensitive acute phase reactant, which may increase by a factor of 100-1000 during the acute phase response. ${ }^{19}$ There was no change in this variable during each of the periods of netball training and in the heavy period of soccer training. The $\mathrm{C}$ reactive protein levels declined during the moderate soccer training period. A similar reduction has recently been shown after nine months of endurance running training, ${ }^{20}$ and it has been suggested that this is the consequence of a systemic anti-inflammatory effect of intense regular exercise.

On balance, the data indicate that an acute phase response is not a consequence of training at levels typical of elite women's netball and soccer squads. Therefore serum concentrations of a range of biochemical variables, most importantly those related to iron metabolism, can be interpreted in these groups, and perhaps others involved in similar levels and forms of training, in the same way as those in the general population. This also indicates the potential for using research findings from complex and invasive studies of non-athletic populations for investigating athletes in court and field sports.

1 Kushner I, Rzewnicki DL. The acute phase response: general aspects. Bailliere's Clin Rheumatol 1994;8:513-30.

2 Fallon KE, Sivyer G, Sivyer K, et al. Changes in haematological parameters and iron metabolism associated with a 1600 kilometre ultramarathon. Br $\mathcal{f}$ Sports Med. 1999;33:27-32.

3 Kushner I. The phenomenon of the acute phase response. Ann N Y Acad Sci 1982:389:39-48.

4 Konijn AM. Iron metabolism in inflammation. Bailliere's Clin Rheumatol 1994;8:829-49.

5 Baynes R, Bezwoda W, Bothwell T, et al. The non-immune inflammatory response: serial changes in plasma iron, iron binding capacity, lactoferrin, ferritin and C-reactive protein. Scand f Clin Lab Invest 1986;46:695-704.

protein. Scand F Cin Lab Invest 1986;46:695-704.
6 Weight LW, Alexander D, Jacobs P. Strenuous exercise: analogous to the acute phase response? Clin Sci 1991;81: 677-83

7 Dufaux B, Hoffken K, Hollman W. Acute phase proteins and immune complexes during several days of severe physical exercise. In: Knuttgen, HG, ed. Biochemistry of exercise. International series on sport sciences, vol 13. Champaign: Human Kinetics, 1983:356-62.

8 Poortmans JR, Haralambie G. Biochemical changes in a $100 \mathrm{~km}$ run: proteins in serum and urine. Eur $\mathcal{F}$ Appl Physiol 1979;40:245-54

9 Taylor C, Rogers G, Goodman C, et al. Hematologic, ironrelated, and acute-phase protein responses to sustained strenuous exercise. F Appl Physiol 1987;62:464-9.

10 Dickson DN, Wilkinson RL, Noakes TD Effects of ultra-marathon training and racing on haematologic parameters and serum ferritin levels in well trained athletes. Int $\mathcal{F}$ Sports Med 1982;3:111-17.

11 Seiler D, Nagel D, Franz H, et al. Effects of long distance running on iron metabolism and haematological parameters. Int $\mathcal{F}$ Sports Med 1989;19:357-62.

12 Strachan AF, Noakes TD, Kotzenberg G, et al. C reactive protein concentrations during long distance running. BMf 1984;29:1249-51.

13 Malczewska J, Blach W, Stupnicki R. The effects of physical exercise on the concentrations of ferritin and transferrin receptor in plasma in female judoists. Int $\mathcal{F}$ Sports Med 2000;21:175-9.

14 Witte DL. Can serum ferritin be effectively interpreted in the presence of the acute phase response? Clin Chem 1991; 37:484-5.

15 Neilsen P, Nachtigall D. Iron supplementation in athletes. Current recommendations. Sports Med 1998;26:207-16.

16 Chatard J, Mujika I, Guy C, et al. Anaemia and iron deficiency in athletes. Practical recommendations for treatment. Sports Med 1999;27:229-40.

17 Mast AE, Blinder MA, Gronowski AM, et al. Clinical utility of the soluble transferrin receptor and comparison with serum ferritin in several populations. Clin Chem 1998;44: $45-51$.

18 Ali MAM, Luxton AW, Walker WHC. Serum ferritin concentration and bone marrow iron stores: a prospective study. Can Med Assoc F 1978;118:945-6.

19 Jupe D. The acute phase response and laboratory testing. Aust Fam Physician 1996;25:324-9.

20 Mattusch F, Dufaux B, Heine O, et al. Reduction of the plasma concentration of C-reactive protein following nine months of endurance training. Int $\mathcal{f}$ Sports Med 2000;21: $21-4$.

\section{Take home message}

In female netball and soccer players, interpretation of haematological and biochemical variables that may be components of the acute phase response need not take this response into account. As this study was of elite athletes training at relatively high levels, this guideline can probably be applied to the large number of athletes training in these sports at lower levels. It is reasonable to conclude that it also applies to male and female athletes involved in other court and field sports, but this requires confirmation. 